\section{A ÁREA DE CIÊNCIA DA INFORMAÇÃO NA CAPES}

Em 2016, a Capes atendeu uma antiga e sempre renovada reivindicação dos Programas de Pós-Graduação da área Ciências Sociais Aplicadas I, alterando esta denominação para Comunicação e Informação, abrangendo a Ciência da Informação, Comunicação e Museologia.

O Documento de Área da Comunicação e Informação, elaborado pela comunidade científica, com apoio da Capes, em 2016, ressalta o crescimento da área:

[...] entre 1996 e 2014, que contava então com 62 cursos de mestrado e 33 cursos de doutorado, representando cerca de 1,7\%dos cursos de pósgraduação credenciados pela CAPES [...]. As taxas de expansão superiores às médias da CAPES refletem sobretudo o crescente interesse acadêmico e profissional pelo campo da comunicação e informação na sociedade contemporânea.'

Dentre os 23 Programas da área de Ciência da Informação, observamos que 11 Programas estão sediados na Região Sudeste, sete na Região Nordeste, três na Região Sul, e dois, respectivamente, nas Regiões Norte e CentroOeste.

Em São Paulo, os Programas de PósGraduação em Ciência da Informação estão sediados nas Universidades de São Paulo, Estadual Júlio de Mesquita Filho e de São Carlos. No Rio de Janeiro, os Programas estão sediados nas Universidades Estadual do Rio de Janeiro, nas Universidades Federais do Rio de Janeiro ${ }^{2}$ e de Minas Gerais, na Universidade Federal
Fluminense e na Fundação Casa de Rui Barbosa. No Sul, os Programas estão sediados em Santa Catarina, nas Universidades Federal e Estadual; e na Região Norte, o Programa está sediado na Universidade Federal do Pará. Nesse contexto, reproduzimos um quadro ${ }^{3}$ do novo território da Pós-Graduação em Ciência da Informação, de modo que os interessados possam conhecer os novos espaços de formação de pesquisadores, no Brasil

Trata-se de um campo científico estruturado ao longo de quase 50 anos de atuação na pós-graduação do Brasil, que trabalha em parceria com inúmeras instituições de ensino e pesquisa estrangeiras, com um campo de abrangência de centenas de pesquisadores atuantes, nacional e internacionalmente.

De modo que, nesta oportunidade, congratulamo-nos com a comunidade da Ciência da Informação no Brasil, por seu trabalho incessante na ampliação desse campo científico, pelas oportunidades de formação de pesquisadores e de compartilhamento oferecidas pelos programas de pós-graduação e periódicos publicados regularmente na área. E desejamos que esse crescimento permaneça e frutifique, de modo que o campo da informação, através de seus pesquisadores, mantenha uma caminhada inovadora e crítica na sociedade em rede.

\section{Gustavo Henrique de Araújo Freire} Isa Maria Freire

Editores

Quadro 1 - Comunicação e Informação:

Cursos recomendados pela Capes

\footnotetext{
I Disponível em: http://www.capes.gov.br/component/content/article/44 avaliacao/4662-ciencias-sociais-aplicadas-i.

2 Em convênio com o Instituto Brasileiro de Informação em Ciência e Tecnologia (IBICT).
}

$3 \quad$ No final do texto. 


\section{Instituição de Ensino \\ Total de Programas de pós- Totais de Cursos de graduação pós-graduação}

\begin{tabular}{|c|c|c|c|c|c|c|c|c|c|c|}
\hline & UF & Total & ME & DO & MF & ME/DO & Total & ME & DO & MF \\
\hline FUNDAÇÃO CASA DE RUI BARBOSA & RJ & 1 & 0 & 0 & 1 & 0 & 1 & 0 & 0 & 1 \\
\hline $\begin{array}{l}\text { FUNDAÇÃO UNIVERSIDADE FEDERAL DE } \\
\text { SERGIPE }\end{array}$ & SE & 1 & 0 & 0 & 1 & 0 & 0 & 0 & 0 & 0 \\
\hline UNIVERSIDADE DE BRASÍLIA & DF & 1 & 0 & 0 & 0 & 1 & 2 & 1 & 1 & 0 \\
\hline UNIVERSIDADE DE SÃO PAULO & SP & 2 & 0 & 0 & 1 & 1 & 3 & 1 & 1 & 1 \\
\hline $\begin{array}{l}\text { UNIVERSIDADE DO ESTADO DE SANTA } \\
\text { CATARINA }\end{array}$ & $\mathrm{SC}$ & 1 & 0 & 0 & 1 & 0 & 1 & 0 & 0 & 1 \\
\hline UNIVERSIDADE ESTADUAL DE LONDRINA & PR & 1 & 1 & 0 & 0 & 0 & 1 & 1 & 0 & 0 \\
\hline $\begin{array}{l}\text { UNIVERSIDADE ESTADUAL PAULISTA } \\
\text { "JÚLIO DE MESQUITA FILHO" }\end{array}$ & SP & 1 & 0 & 0 & 0 & 1 & 2 & 1 & 1 & 0 \\
\hline UNIVERSIDADE FEDERAL DA BAHIA & BA & 1 & 0 & 0 & 0 & 1 & 2 & 1 & 1 & 0 \\
\hline UNIVERSIDADE FEDERAL DA PARAÍBA & PB & 1 & 0 & 0 & 0 & 1 & 2 & 1 & 1 & 0 \\
\hline UNIVERSIDADE FEDERAL DE MINAS GERAIS & MG & 2 & 0 & 0 & 0 & 2 & 4 & 2 & 2 & 0 \\
\hline UNIVERSIDADE FEDERAL DE PERNAMBUCO & $\mathrm{PE}$ & 1 & 0 & 0 & 0 & 1 & 1 & 1 & 0 & 0 \\
\hline $\begin{array}{l}\text { UNIVERSIDADE FEDERAL DE SANTA } \\
\text { CATARINA }\end{array}$ & $\mathrm{SC}$ & 1 & 0 & 0 & 0 & 1 & 2 & 1 & 1 & 0 \\
\hline UNIVERSIDADE FEDERAL DE SÃO CARLOS & SP & 1 & 1 & 0 & 0 & 0 & 1 & 1 & 0 & 0 \\
\hline UNIVERSIDADE FEDERAL DO CARIRI & $\mathrm{CE}$ & 1 & 0 & 0 & 1 & 0 & 1 & 0 & 0 & 1 \\
\hline UNIVERSIDADE FEDERAL DO CEARÁ & $\mathrm{CE}$ & 1 & 1 & 0 & 0 & 0 & 1 & 1 & 0 & 0 \\
\hline $\begin{array}{l}\text { UNIVERSIDADE FEDERAL DO ESTADO DO RIO } \\
\text { DE JANEIRO }\end{array}$ & RJ & 2 & 0 & 0 & 2 & 0 & 2 & 0 & 0 & 2 \\
\hline UNIVERSIDADE FEDERAL DO PARÁ & PA & 1 & 1 & 0 & 0 & 0 & 1 & 1 & 0 & 0 \\
\hline $\begin{array}{l}\text { UNIVERSIDADE FEDERAL DO RIO DE } \\
\text { JANEIRO }\end{array}$ & $\mathrm{RJ}$ & 1 & 0 & 0 & 0 & 1 & 2 & 1 & 1 & 0 \\
\hline $\begin{array}{l}\text { UNIVERSIDADE FEDERAL DO RIO GRANDE } \\
\text { DO NORTE }\end{array}$ & $\mathrm{RN}$ & 1 & 0 & 0 & 1 & 0 & 1 & 0 & 0 & 1 \\
\hline UNIVERSIDADE FEDERAL FLUMINENSE & RJ & 1 & 0 & 0 & 0 & 1 & 2 & 1 & 1 & 0 \\
\hline \multicolumn{2}{|l|}{ Totais } & 23 & 4 & 0 & 8 & 11 & 32 & 15 & 10 & 7 \\
\hline
\end{tabular}

Legendas: ME: Mestrado Acadêmico; DO: Doutorado; MF: Mestrado Profissional; ME/DO: Mestrado e Doutorado Fonte: Disponível em: http://www.capes.gov.br/cursos-recomendados. 